\title{
Monitoring of Phase Distribution when Controlling Safety of Transport Processes and Hydrocarbon Storage
}

\author{
Yuri Zemenkov ${ }^{1}$, Maria Zemenkova ${ }^{1, *}$, Alexey Gladenko ${ }^{2}$ and Nikolay Zakirov ${ }^{1}$ \\ ${ }^{1}$ Tyumen Industrial University, Volodarskogo st. 38, Tyumen, Russia \\ ${ }^{2}$ Omsk State Technical University, st. Mira 11, Omsk, Russia
}

\begin{abstract}
Based on statistical processing of an array of information and summarizing the experimental data in IUT, analytical dependences for calculating the coefficient of the phase equilibrium under various pressures and temperatures were obtained. The proposed equations for the first time used the quantitative composition of hydrogen which determines, according to the authors, the volatility of the oil or condensate fraction and greatly simplifies relevant calculations in comparison with known analogues. To find the coefficients a computer program was developed that implements a method of non-linear regression. The developed algorithm was tested and proved to be very convenient and efficient for a rapid assessment of experimental studies.
\end{abstract}

\section{Introduction}

Common methods of characterizing volatility of petroleum and petroleum products can be divided into two groups: experimental (direct and indirect) and theoretical. Direct methods include techniques for direct measurement of the volume of liquid before and after evaporation or calculating the volume (mass) of vapor [11-14]. Direct determination of hydrocarbon emissions is extremely difficult and in some cases even impossible, especially for short-term storage encountered in emergency situations. An important task when calculating the storage and transport conditions is correctly defining constants of hydrocarbons phase equilibrium [18-21].

It should be recognized that a priority in the study of hydrocarbon phase equilibrium constants belongs to American Petroleum Institute (API) which charts are widely used in oil refining [6-10]. Also known is a NGPSA technique allowing to determine the value of kei at temperatures reaching $430{ }^{\circ} \mathrm{C}[1-5]$. Published print versions of these techniques are very complicated and inconvenient for practical use, and computerized schemes are the property of the developers: Dowling, Leslie, Stall, Soavva, Todd, Hedden, Sherwood et al. Among Russian publications can be noted developments of A.I. Gritsenko, G.R. Gurevich, V.P. Mamun, T.D. Ostrovsky, G.M. Yaryshev, T.A Omutova, V.I. Shilov, S.F. Barmin, D.P. Vasilev [1-5,10, 11-20]., etc.

\footnotetext{
* Corresponding author:muzemenkova@mail.ru
} 
Also, the Siberian Research Institute (SibNIINP) developed a technique of determining the coefficient kei of fractions and components depending on the molecular weight of various oils in West Siberia as applied to the oilfield conditions of high absolute pressure [1].

At present, a significantly large amount of experimental material has already been accumulated in Russia [15-17]; however, the value of constant $k_{e i}$ can be used in calculations of vapor-liquid equilibrium only for systems adequate to the laboratory ones. The latter condition greatly reduces the advantages of such information if phase composition constantly changes, for example, when liquid hydrocarbon mixtures evaporate from the exposed surface. It is known [2] that under near-atmospheric pressures coefficients of component phase distribution $k_{e i}$ are functions of the system temperature t only.

For hydrocarbon mixtures of arbitrary nature the equation when modeling dependencies can be $k_{e i}=f_{i}(t),\{x\}$ :

$$
k_{e i}=f_{i}(t)
$$

Based on statistical modeling of an array of information and summarizing the experimental data in IUT analytical dependencies for calculating the coefficient $k_{p i}$ of the phase equilibrium under low pressures $(0.1 \div 1.2 \mathrm{MPa})$ and temperatures from 273 to $330{ }^{\circ} \mathrm{K}$ were obtained. In the proposed equations the quantitative composition of hydrogen is used for the first time determining the volatility of the oil or condensate fraction. This assumption greatly simplifies relevant calculations, compared to foreign counterparts, such as the well-known Stall formula

$$
\lg k_{e}=A+1000 B /(C+T)
$$

where A, B and C - empirical coefficients.

For alkanes dependencies are obtained:

$$
A=6.8-2.7 n_{n}-p / p_{a t} \quad \text { and } \quad B=2+0.54 n_{n},
$$

for alkenes and arenes

$$
A n=6.8-2.7 n_{n p h}-p / p_{a t}, \quad B_{n}=\left(2+0.54 n_{n p h}-17\left(n_{n}-n_{n p h}\right) n_{n p h}-1\right.
$$

where $n_{n}$ - the homolog serial number (alkanes); $n_{n p h}-$ the number of hydrogen atoms in naphthenes (cyclanes) or arenes; $p$ and $p_{a t}$ - absolute and atmospheric pressure, correspondingly.

A rather high accuracy of calculations should be noted, particularly in relation to hydrocarbons of the methane series. The proposed technique has been tested in determining the values of more than 100 coefficients. Satisfactory results are obtained also when determining the coefficients of various hydrogen-containing compounds such as aniline $\left(\mathrm{C}_{6} \mathrm{H}_{7} \mathrm{~N}\right)$, chloroform $\left(\mathrm{CHCl}_{3}\right)$, ammonia $\left(\mathrm{H}_{3} \mathrm{~N}\right)$, methanol, ethanol and others, although calculations error is higher and reaches $10 \%$. For practical calculations we can recommended the dependence

$$
\lg k_{e}=\ln \left[(A+1000 B T-1) n_{n}\right]
$$

The resulting equations (2-5) are adequate according to the Fisher criterion and are characterized by small error (eg, less than $3 \%$ for paraffinic hydrocarbons) with the multiple correlation coefficient $\mathrm{R}=0.98$. Deviation of the calculated values of the phase distribution coefficient $k_{e i}$ from those published in reference books is given in Table 1 . 
Table 1. Values of the phase equilibrium coefficient $k_{e i}$ (at $T=293 \mathrm{~K}$ and $p=0.098 \mathrm{MPa}$ )

\begin{tabular}{|c|c|c|c|c|c|c|}
\hline \multirow{2}{*}{\begin{tabular}{c} 
Method of determining $\boldsymbol{k}_{\boldsymbol{e}}$ \\
\cline { 2 - 7 }
\end{tabular}} & $\mathbf{C H}_{\mathbf{4}}$ & $\mathbf{C}_{\mathbf{2}} \mathbf{H}_{\mathbf{6}}$ & $\mathbf{C}_{\mathbf{3}} \mathbf{H}_{\mathbf{8}}$ & $\mathbf{C}_{\mathbf{4}} \mathbf{H}_{\mathbf{1 0}}$ & $\mathbf{C}_{\mathbf{5}} \mathbf{H}_{\mathbf{1 2}}$ & $\mathbf{C}_{\mathbf{6}} \mathbf{H}_{\mathbf{1 4}}$ \\
\hline $\begin{array}{c}\text { By the nomogram of } \\
\text { Zarembo K.S. }\end{array}$ & 165.00 & 25.50 & 7.50 & 3.00 & 0.53 & 0.15 \\
\hline By the Cox graph & - & 39.50 & 9.20 & 2.40 & 0.60 & 0.16 \\
\hline By the formula (5) & 165.57 & 24.94 & 7.83 & 2.80 & 0.58 & 0.17 \\
\hline
\end{tabular}

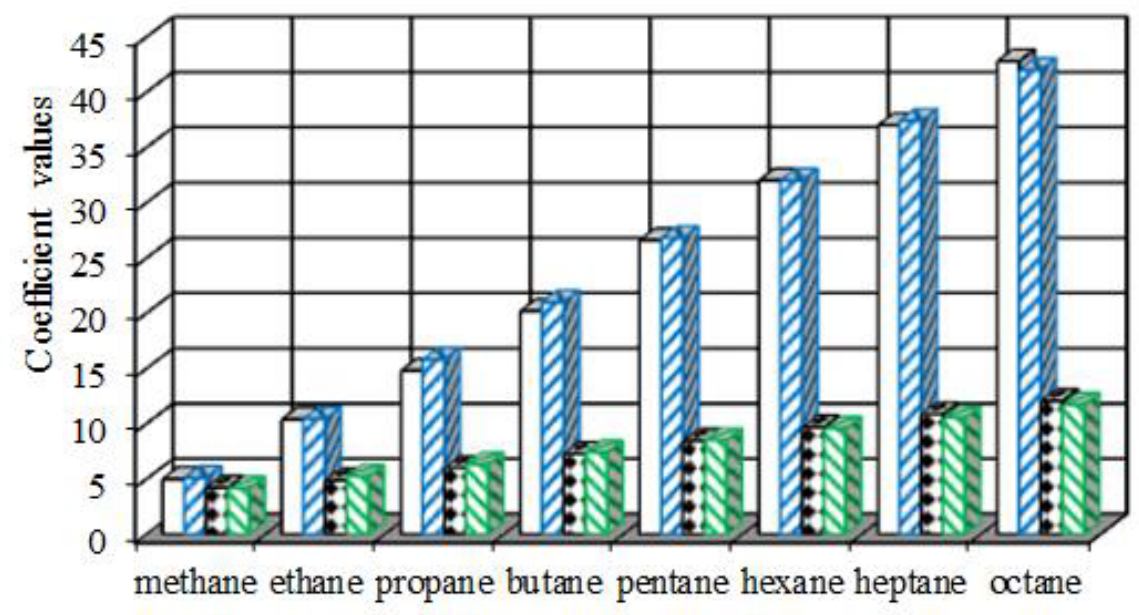

\section{$\square$-Aculc $\mathbf{\Xi}$-Atab $\mathbf{B}$-Balc $\square$-Btab}

Fig. 1. Coefficient values A and B for alkanes (paraffin hydrocarbons).

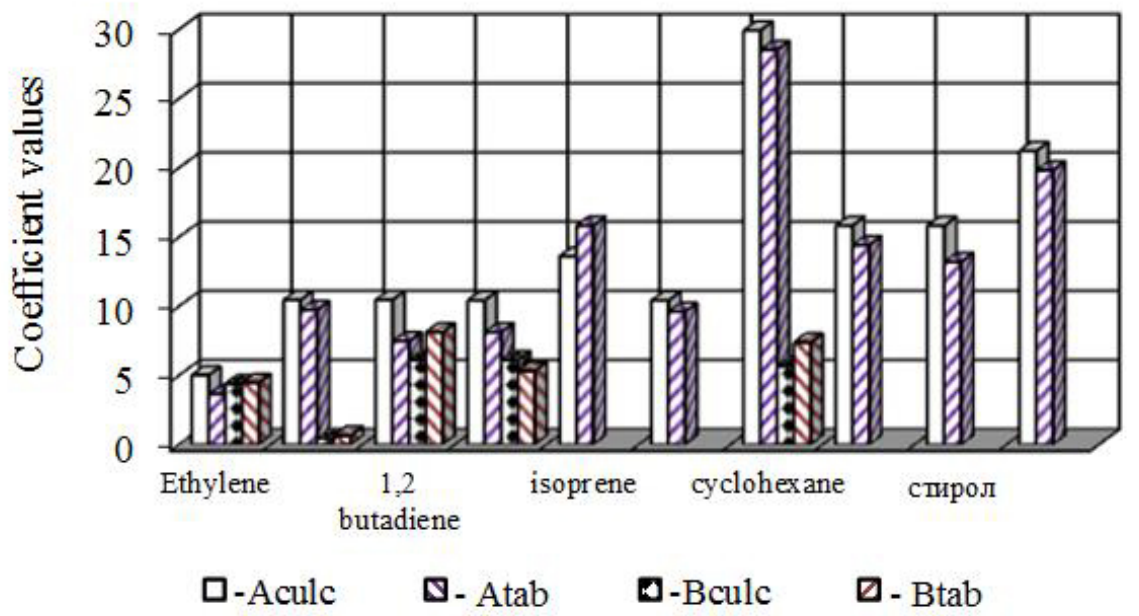

Fig. 2. Coefficient values $A$ and $B$ for alkenes and arenes. 
To determine the functional dependence of the coefficients of the phase component distribution $k_{e i}$ on the system temperature $t$ we apply regression analysis (approximation of functions according to the least squares method), substituting $k_{e i}$ for the virtual value $Y_{i}$.

Dual regression analysis providing the least mean square error determines parameters of the empirical linear dependence

$$
Y(T)=b_{1} t+b 0
$$

characterizing the relationship between a certain number $\mathrm{N}$ of value pairs $t_{i}$ and $Y_{i}$.

Graphically, this problem can be represented as follows: - on the field of a set of points $t_{1}, Y_{i}$ of the plane $t_{Y}$ the required function must be built so that the value of all deviations met the condition

$$
U=\sum_{i=1}^{N}\left[Y_{i}-Y\left(t_{i}\right)\right]^{2}=\min
$$

where $Y\left(t_{i}\right)$ is determined by (6).

Thus, non-linear dual regression was reduced to obtaining a predetermined non-linear dependence $Y(t)$ (non-linear in the independent variable $t$, but linear in the parameters of this dependence).

The pattern of changes in the coefficients of the components phase distribution $k_{e i}$ from the system temperature $t$ defined by experimental data was close to exponential

$$
k_{e i}=A_{i} \cdot e^{0.037 C_{i} \cdot t}
$$

As an example, Table 2 shows the values of the coefficients for pure components of the mixture.

Table 2. Values of coefficients for pure hydrocarbons

\begin{tabular}{|c|c|c|c|c|c|c|c|c|}
\hline \multirow{3}{*}{ Coefficients } & \multicolumn{7}{|c|}{ Components } \\
\cline { 2 - 9 } & $\mathbf{C H}_{\mathbf{4}}$ & $\mathbf{C}_{\mathbf{2}} \mathbf{H}_{\mathbf{6}}$ & $\mathbf{C}_{\mathbf{3}} \mathbf{H}_{\mathbf{8}}$ & $\mathbf{i C}_{\mathbf{4}} \mathbf{H}_{\mathbf{1 0}}$ & $\mathbf{C}_{\mathbf{4}} \mathbf{H}_{\mathbf{1 0}}$ & $\mathbf{i C}_{\mathbf{5}} \mathbf{H}_{\mathbf{1 2}}$ & $\mathbf{C}_{\mathbf{5}} \mathbf{H}_{\mathbf{1 2}}$ & $\mathbf{C}_{\mathbf{6}} \mathbf{H}_{\mathbf{1 4}}$ \\
\hline$A_{i}$ & 127.14 & 17.31 & 4.55 & 1.57 & 1.08 & 0.32 & 0.24 & 0.055 \\
\hline$C_{i}$ & 0.324 & 0.529 & 0.622 & 0.757 & 0.811 & 0.973 & 1.027 & 1.270 \\
\hline
\end{tabular}

The pattern of changes in the coefficients of the phase distribution $k_{p i}$ of narrow fractions from the system temperature $t$, is also close to exponential and is adequately approximated by the following function:

$$
k_{e i}=e^{0.037\left(C_{i} \cdot t-t_{B}\right)}
$$

where $t_{B}$ - the average boiling point of the fraction, ${ }^{\circ} \mathrm{C}$.

Regression models are adequate according to the Fisher criterion and are characterized by small error (not more than $5 \div 15 \%$ ) with the multiple correlation coefficient $\mathrm{R}=0.97$. As an example, for a number of hydrocarbons Fig. 3 graphically shows deviation of the calculated values of the phase distribution coefficient from the experimental.

Thus, the developed set of equations allows calculating $k_{p i}$, which simplifies the tasks of operational estimation of phase distribution, especially if information on the hydrocarbon mixture composition is incomplete. 


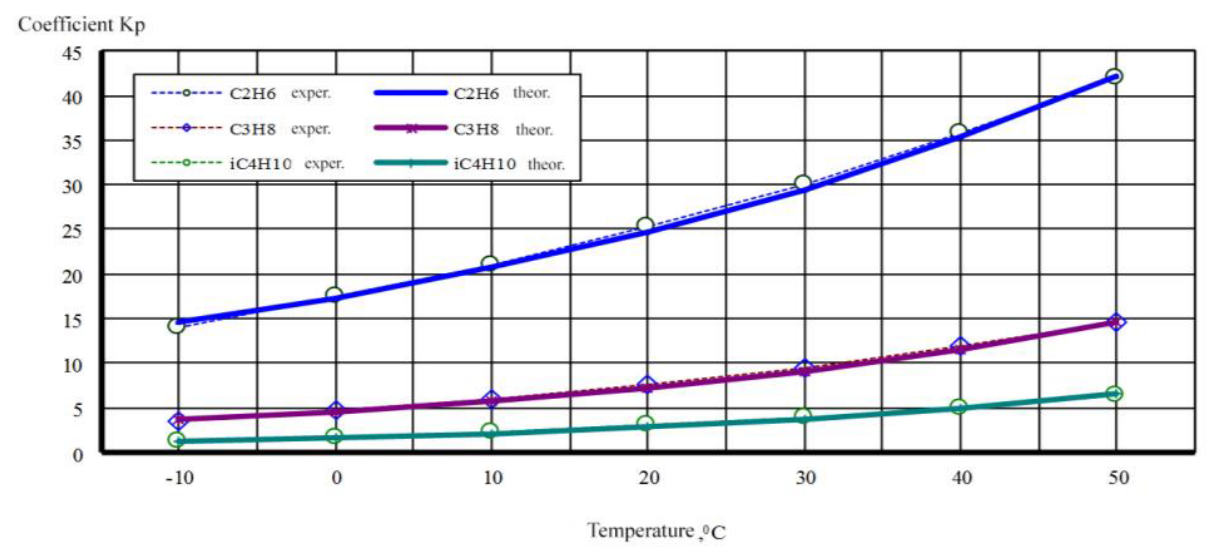

Fig. 3. Deviation of calculated values of phase distribution coefficient from the experimental (on the example of ethane, propane and butane).

\section{Conclusions}

To find the coefficients $\mathrm{Ai}$ and $\mathrm{Ci}$ a computer program was developed that implements a method of non-linear regression. The developed algorithm and obtained dependences proved to be very convenient and efficient for a rapid assessment of experimental studies

\section{References}

1. V. Shilov, Abstract of thesis of Candidate of Technical Sciences (TSOGU, Tyumen, 1984)

2. V. Antipyev, Yu. Zemenkov, N. Kudryavtseva, UMN Z and SZS (Tyumen, 1985)

3. V. Kurushina, Yu. Zemenkov, WIT Transactions on Ecology and the Environment 190(2), 881-888 (2014)

4. V. Antip'ev, A. Nevolin, Yu. Zemenkov, Neftyanoe Khozyaistvo - Oil Industry 10, 4648 (1981)

5. V. Antipyev, V. Arkhipova, Yu. Zemenkov, N. Kudryavtseva, The instruction on calculation of losses of oil at refusals on the main oil pipelines of the Western and Northwest Siberia (TSOGU, Tyumen, 1986)

6. S. Dudin, Yu. Zemenkov, A. Shabarov, N. Saranchyn, Higher Educational Institutions News. Oil and gas 6, 63-68 (2010)

7. I. Alexandrov, Distillation and rectification in oil processing (Chemistry, Moscow, 1981)

8. Yu. Zemenkov, V. Shalay, M. Zemenkova, Procedia Engineering 113, 254-258 (2015)

9. Yu. Zemenkov, V. Shalay, M. Zemenkova, Procedia Engineering 113, 312-315 (2015)

10. Yu. Zemenkov, Dissertation of Doctor of Technical Sciences (TSOGU, Tyumen, 1999)

11. G. Filippov, I. Malkin, L. Vilenkina, Theoretical bases of chemical technology 5, 772774 (1989)

12. M. Lurie, Neftyanoe khozyaystvo - Oil Industry 9, 111-113 (2013)

13. L M. Lurie, DOI: 10.1002/9783527626199 (2009)

14. S. Kudakaev, F. Aminev, V. Galiakbarov, G. Korobkov, V. Kovshov, Gazovaya Promyshlennost 5, 10 (2004)

15. E. Kurushina, V. Kurushina, Assessment of the smart growth, Life Science Journal 11(11), 517-521 (2014) 
16. V. Kurushina, Yu. Zemenkov, E. Kurushina, Fundamental researches 2-8, 1632-1636 (2015)

17. E. Kurushina, Canadian Journal of Science, Education and Culture 2(6), 378-384 (2014)

18. V. Shilov, Abstract of thesis Cand.Tech.Sci. (TSOGU, Tyumen, 1984)

19. R. Mamadaliev, V. Kuskov, Yu. Zemenkov, A. Popova, Applied Mechanics and Materials 770, 19-22 (2015)

20. Yu. Zemenkov, Higher Educational Institutions News. Oil and Gas 3, 78-82 (1998)

21. S. Ueyles, Phase balance in chemical technology (Mir, Moscow, 1998)

22. Ya. Gorelik, A. Shabarov, Yu. Sysoyev, Earth's Cryosphere 12(1), 59 (2008) 